\title{
The Impact of Globalization on Curriculum Innovation in the New Millennium
}

\author{
Adetunji, Akeem Adedeji (Ph.D.) \\ Bamidele, Emmanuel Folorunso (Ph.D.) \\ Awodele, Babatunde Adedeji (M.Ed) \\ Ojediran, Isaac Ayodele. (M.Ed)
}

Department of Special Education and Curriculum Studies, Obafemi Awolowo University, Ile-Ife.

Doi:10.5901/ajis.2013.v2n2p471

\begin{abstract}
This paper took a critical look at the new global face and challenges it poses on nation's curriculum development and classroom learning. It identified conceptual framework of globalization, its critique and importance of the need for a paradigm shift from the old established order. Suggested reasons why globalization may not match curriculum development in Nigeria in this century were also discussed.
\end{abstract}

\section{Introduction}

Globalization began to be widely used in the academic world in the 1990s, but it had been arguably formulated much earlier. Wagner (2004) refers to globalization as a new condition for our time and asserts that if such a condition has generated considered ambivalent responses, "there is also some urgency in addressing" the issue.

According to Ehindero (2006), teaching is a normative and interactive human process involving complex decisionmaking on different aspects of classroom interactions. In his opinion, sometimes we draw an analogy between teaching and marketing or selling. The teacher, like the seller, has a product (packaged knowledge) to 'sell' to an active, critically minded 'buyers'-the students. To sell the knowledge or message, call it concept, generalization, principles or laws embedded in the different disciplines of the school curriculum, the teacher has to make the product 'attractive' to the buyers. Truly, the era of globalization has arrived with many implications on national and regional stability (Albassam, 2007). Globalization is about the monumental structural change occurring in the process of production and distribution in the global economy (Albassam, 2007). Albassam's view of globalization is in line with Ehindero's juxtaposition of teacher -seller and student -buyer. The old sellers, that is, the teachers must be awakened of new techniques of production and distribution currently going on in the globe. Curriculum planners must be aware of globalization to effectively innovate and that should include effective teacher education.

The global system of production and distribution is now progressing from the Fordist-Taylorist development model to one based on Innovation-Mediated production. Fordism-Taylorism was the dominant paradigm of the twentieth century and rested upon factory system and mass production, application of scientific management and the moving assembly line. The newly emerging Innovation-Mediated production represents a fundamental shift from burning mental and physical labour to the application of knowledge to the production process itself. Globalization, unlike 20th century social and economic development, will cause fundamental rather than merely incremental educational change. The real transformation in life occurs when the nature of relationship has been revisited and the member of any given system share new meanings. Traditional institutions and models of education, however still prepare people for the world of passing on recipes for 'thinking, seeing and living'. This focus on recipes rest on an assumption that learners seek reassurance and answers from their learning experience and would somehow be troubled and anxious in the face of uncertainty and ambiguity. These recipes or algorithmic ways of approaching problems and understanding the world, however, are increasingly maladapted to a world characterized by rapid, never-ending, pulsating and interconnected change. When recipes and recipe-learning no longer provide a basis for making sense of the world let alone assigning 
meaning, anxiety and fear are the end results. This is the main reason why at all levels of education, there is need to develop 'new habits of the mind' for a 'new world'. There should be movement from recipes and algorithmic thinking toward complexities and complex thinking. Problem-Based Learning (PBL) is an evidence, or entrance movement towards non-algorithmic thinking. Teachers in globalised learning assume the role of the cognitive and meta-cognitive coach, rather than knowledge holders and disseminators. Students assumed the role of active problem solvers, decisionmakers, rather than passive learners. In the teaching and learning process, information is shared, but knowledge is a personal construction of the learner. Thinking is fully articulated and held to strict benchmarks.

\section{Conceptual Framework of Globalisation, Internationalisation and the Transnational}

Wagner (2004) lists three generally accepted dimension of globalization to include Economic, Cultural and Political. Economy refers to the creation of a world market; cultural refers to the contradictory but simultaneous emergence of a homogenous world culture and multicultural situation as a result of trans-national migration. Political, as a weak dimension, refers to the alleged decline of the national and emergent elements of political globalization but not as strong as the economic and cultural dimensions. Wagner further asserts that we should try and understand globalization and participate in the multi-dimensional and complex global process rather than stepping back from the sweeping wave of the technological and economic forces. Globalization signals homogeneity even through in the realm of culture, the movement is paradoxical, toward both homogeneity and heterogeneity.

Due to the critiques of globalization in its underlying tendency toward homogeneity, the internalization movement in the field of American curriculum studies has deliberately chosen another term, "internationalization" to contest the control of Globalization one while responding to changing contemporary world situations. However, internationalization as a concept has the potential to counteract the economic standardization and cultural imperialism under the term "globalization". Pinar (2004) points out that both the "inter" space and the "locality" implied in affirming international conversations are conditions for sustaining a dynamic movement between locality and globalness. The usage of "internationalization" rather than "globalization" demonstrates a stronger sense of conversation through "in between" fluid spaces whose multiplicity and differences are neither excluded nor self- contained.

While challenging narrow-minded nationalism, we cannot forget that nationalism, historically, was linked with the de-colonization struggles of many "Third World" countries. The neo-colonization tendency of globalization still needs to be contested from national, regional and local levels. In order to keep the generative tension of the local, the interstitial and the global. Gough (2003) suggests that "internationalizing curriculum inquiring might best be understood as a process of creating transnational spaces in which scholars from different localities collaborate in refraining and decentering their own knowledge traditions and negotiate trust in each other's contributions to their collective work". The very usage of "trans' indicates an experiencing of the boundary and an effort to go beyond that boundary. Such transnational spaces not only sustain hybrid movements but also support embodied work to negotiate collaborative trust. Embodied work requires keeping in touch with the concreteness of reality, subjectivity and life instead of being lost in the virtual world.

\section{Globalization-Indigenization Dynamics.}

It should be noted that since the less developed countries are not located at the center of globalization, their responses usually demonstrate the tension between globalization and indigenization. Leonardo Gamier explains that there are two extreme responses to globalization from the less advantage position: one is accepting it and trying to catch up with it, the other is using ones own cultural tradition to resist it. Between these two positions are various efforts to live with the tensions, challenges and possibilities opened up by the dynamics between the global and the local. In general globalization implies homogeneity, unity and oneness while indigenization implies heterogeneity, multiplicity and pluralism. Wang (2002) and Yang (2004) point out that globalization and indigenization as another concepts are related and they form a dialectic couple. Gough (2003) points out that what is taken as universal knowledge such as science is actually localized knowledge emerging from a specific social and historically western context. When the notions of the global and the local are both problematic and become fluid, the relationship between them is no longer perceived as a connection between two static entities, but become an intertwined, multilayered and moving relationship to form a network with complex links. In such a process, the global and local mutually influence and transform each other, creating what Wang prefers to call a third space that incorporates both "inter" space and trans spaces. Wang (2002) suggests that Chinese education needs to find 'third way' beyond rootless total westernalization and narrow-minded ethnocentrism. 
Xiang (2001) analyses the notion of indigenization through another angle, shifting the focus to how to promote creativity from within. He makes a distinction between nativization and indigenous evolution. Nativization is a process in which Western culture is assimilated into native culture, while indigenous evolution is a process in which native culture transforms itself to grow beyond itself.

Nativisation inevitably has an element of internationalised colonisation to serve the interest of the powerful while the indigenisation has an element of active learning for the purpose of self-cultivation. The overlapping but different foci of Wang's and Xiang's discussions reveal the tension between globalisation and indigenisation. When the distabilising power of globalisation which calls for the local out of its static conditions, as Wang emphasises, is situated in "the third space" (Aoki, 2005; Bliabba, 1990; Wang, 2002). Xiang's indigenous evolution becomes more possible. Such a space implies not only a sense of self-understanding and respect for others but also a necessity to go beyond the locality to enter into concretive globalness.

\section{Curriculum in an Era of Globalisation}

In the world of teaching, the connection between the democratisation of the global society and the democratisation of self requires a mode of pedagogy. Autobiography (Currere) in the field of curriculum studies is formulated as a meaning making process in which teacher and student engage educational experiences in a transformative way by linking school knowledge with life history.

Autobiography has contributed to the shift in the focus of the curriculum field from techniques to personhood. In the new wave of internationalisation meanings of personhood are stretched to meet the global. Raising the question on how to re-think the nature of knowledge, modes of knowing and visions of teaching, the implications of globalisation for pedagogy is essential. McDermott (2008) insists that "face-to-face pedagogical relationships cannot be replaced by the computer since a systemic move away from interpersonal embodiment is a move away from who are and how we experience ourselves as human beings, ineluctably". By contrast, Juishree and Odin (2004) believe in the power of new technologies and calls for "a paradigm change in the educational process" enabled by multidisciplinary hyper-learning, web-mediated teaching and interactive modes of pedagogy. The new modes of knowing enabled by technologies have indeed undermined the teacher's traditional authority and require new teaching strategies that are more learner-centered, more nonlinear and more cross-disciplinary. Teachers need to allow the challenges of new educational experiences to come back on themselves and engage self-transformation.

Furthermore, the challenges that teaching is facing are not merely technological issues, but involve fundamental questions about humanness that we are co-creating in responding to this specific global time and space.

Gazetas (2003) opines that global migration makes dialogue possible in "our daily interpersonal relationships. $\mathrm{He}$ conceptualises the third space to reconstitute "new pedagogies in the interstices between different cultural worlds" Such pedagogies situated in the interstices initiate a process of translation and negotiation in which movements of hybridity lead to the birth of the newness that cannot be anticipated. Wang finds the third space both unsettling and generative. It is unsettling because the process of open-ended inquiry leads in all kinds of directions and the effect of teaching is unpredictable; it is generative because translation across differences and flow among the multiple build up possibilities of new consciousness and new relationships. Both the challenges and possibilities for teaching in an era of globalisation lie in a space in which cultures and identities mutually, if not equally, impact one another. Such a space is not free from conflicts but is filled with ambiguity, paradoxes and complexity and as it shifts, a network of hybrid movements brings new shapes to both the local and the global. In a network, power cannot be over-determinate; possibilities to resist the central control are multiple and specific. Such a space where a pedagogical relationship is situated, allows neither authoritarian from teacher to student, nor merging between teacher and student, but keeping an intergenerational conversation going.

Globalisation impacts information revolution and the information age on curriculum innovations. Formal systems of education come about largely through a context of information scarcity. Indeed, one of the functions of credentials in education systems is to indicate the degree to which an individual has closed the information gap between his/her bank of knowledge and the knowledge resident within the institution of learning. The old assumption in this regard is the one that views the students mind as a container and teachers as wise sages on: the stage, delivering data, information, knowledge and wisdom, to the eagerly awaiting students, whose minds were empty vessel waiting to be filled. The heads were required to plan and innovate, while the rank and file, that is, the hands, were expected to execute boring and repetitious tasks. Schooling systems in this regard renders many aspects irrelevant to the world we actually live in. Education theory should not lag behind in adjusting its paradigms to new demands and realities of globalization which 
required cooperativeness, organization, managements, analyzing, verification, application, interpretation and giving meaning to information. The actual learning paradigm will shift from information acquisition to information management on the part of the learner. The curriculum should spell how to teach students to think and not only to teach them facts. Curriculum in the present globalisation should shift from education for conformity to education for creativity. Sources of the curriculum should be diversified and not confined to textbooks. They could be national, communal and thanks to the multi-media and to the abundance and easy accessibility of information, they could also be international. In the information age, children do not learn in boxes, thus the strict division of curriculum into subject matters does not lead to effective learning. Thinking-based: curricula, which encourage and allow children to think, if handled in an integrated fashion, yield the best results. Bearing this in mind, the sources for a relevant update curriculum in a fast-moving age will rely far less on standardized textbooks. Moreover, with regard to learning objectives, considerable emphasis should be placed on collaboration and team works in classroom interaction.

\section{Conclusion and Recommendation}

Our world of today as well as our world by the future demands a new and improved kind of education to meet challenges and it is important to undertake the task of developing new and improved programmes for the preparation of those who serve in the schools as teachers administrators and educational specialists.

Nigeria government, through education agencies should attend to basic literacy, numeracy and access, together with adjusting their education systems to the dictates of globalization. This is because the world economy and the attendant pressure of globalization and knowledge intensity will not stand still and wait for the local literacy and numeracy development. The world challenges in today's global age call for nations especially developing countries like Nigeria to innovate or evaporate.

\section{References}

Albassam, D. (2007). Globalization and Education presented at the Regional Seminar "The Impact of Globalization on Higher Education and Research in the Arab States" Rabat Morocco.

Aoki, T. (2005). Curriculum in a new key (William F. Pinar \& Rital L. Irwin, Eds). Mahwah, NJ: Lawrence Eribaum.

Bliabba, K. (1990). The third space: Interview with Homi Bhabha in Jonathan Rutherford (Ed.) Identity: Community, culture, difference (pp. 207-221). London: Lawrence \& Wishart.

Ehindero, O.J. (2006). Professionalization: The Unfinished Business of Teacher Education in Introduction to the Teaching Profession (PPI). Literamed Publication Limited, Lagos.

Gazetas, A. (2003). Re-constituting pedagogies: The (im) possibilities for internationalizing curriculum studies,. In Donna Trueit, William E. Doll, Jr., Hongyu Wang \& William F. Pinar (Eds). The Internationalization of curriculum studies (pp. 103-115).

Gough, N. (2003). Thinking globality in environment education: Implications for internationalizing curriculum inquiry. In William F. Pinar (Ed.) International handbook of curriculum research (pp. 53-72). Mahwah, NJ: Lawrence Eribaum.

Xing, Y. (2004)" WTO yushi Beijingxia zhongguo jiaoyu gianyan wenti yanju (Studies on Chinese education at the frontier) Taiyuan, China, Shangxi Educational press.

McDermott, J. (2008). The erosion of face-to face pedagogy. In jaishree K. Odin \& Peter T. Manicas (Eds.). Globalization and higher education (pp. 7 -23) Honolulu: university of Hawaii press.

Juishree K. and Odin, (2004). New technologies and the reconstitution of the university. In Jaishree K. Odin \& Peter T. Manicas (Eds.), Globalization and higher education. (pp. 147-162.) Honolulu: University of Hawaii Press.

Pinar, F. (2004). Introduction In Donna Trueit, William E. Doll., Jr., Hongyu Wang \& William F. Pinar (Eds.,) The international of curriculum studies (pp. 1-13). New York: Peter Lang.

Pinar, F. (2004), What is curriculum theory? Mahwah, NJ: Lawrence Eribaum.

Wagner, P. (2004). Higher education in an era of globalization. In Jaishree K. Odin \& Peter T. Manicas (Eds.,) Globalization and Higher education (pp. 7-23). Honolulu: University of Hawaii Press.

Wang, X (2002). Quangiuhua yuxhongguo jiaoyu (Globalization and Chinese, education). Chengdu: Sichuan People's Press.

Yang, X. (2004). Quangiuhua jincheng zhogng de xuexiao biange (School reform in the process of globalization). Shanghai: East China Normal University Press. 